\title{
Evaluation of Signal-Averaged Electrocardiography for Clinical Diagnosis in Arrhythmogenic Right Ventricular Dysplasia
}

\author{
Keiko SeKiguChI, ${ }^{1} \mathrm{MT}$, Yoshiki Miya, ${ }^{2} \mathrm{MD}$, \\ Yoshiaki KANEKO, ${ }^{2} \mathrm{MD}$, Tsugiyasu KANDA, ${ }^{3} \mathrm{MD}$, Yukihito FuKUMURA, ${ }^{1} \mathrm{MT}$, \\ Nobuo Kotajima, ${ }^{1}$ MT, Junichi TAmurA, ${ }^{3} \mathrm{MD}$, and Isao KobayAshi, ${ }^{1} \mathrm{MD}$
}

\begin{abstract}
SUMMARY
Arrhythmogenic right ventricular dysplasia (ARVD) is a heart muscle disorder of unknown etiology that is characterized pathologically by fibrofatty replacement of the right ventricular myocardium. We investigated the relationship between the electrocardiogram (ECG) appearances and signal-averaged ECG (SAECG) in 7 cases with ARVD, and evaluated the usefulness of SAECG as a screening test to detect patients with ARVD. Compared with the conventional 12-lead ECG, the SAECG detects abnormalities at a higher rate in ARVD patients ( $57 \%$ versus $86 \%$ ). SAECG was more sensitive as a screening test to detect patients with ARVD than 12-lead ECG. (Jpn Heart J 2001; 42: 287-294)
\end{abstract}

Key words: Electrocardiogram, Late potential, Endomyocardial biopsy

PATIENTS with arrythmogenic right ventricular dysplasia (ARVD) are at risk for sudden death. ARVD is a heart muscle disorder of unknown etiology that is characterized pathologically by fibrofatty replacement of the right ventricular myocardium. ${ }^{1-4)}$ Segmental right ventricular disease is usual, but evolution to more diffuse right ventricular involvement and left ventricular abnormalities with heart failure also have been reported. ${ }^{5-8)}$ Familial occurrence is frequent, and several specific genetic abnormalities have recently been described. ${ }^{9-13)}$

The pathophysiology underlying this disease is unknown. Similarly, the hemodynamic changes and arrhythmogenic profile associated with ARVD have not been systematically studied. The present study used signal-averaged electrocardiography (SAECG) as a screening test to identify patients who have ARVD and to determine the clinical significance of this disorder. Among several ways to analyze the SAECG, we selected the vector magnitude method of Ozawa, et al..$^{14)}$ This method is widely used in Japan and its normal distributions have already beer reported in a Japanese population. ${ }^{15}$ )

From ${ }^{1}$ Department of Laboratory Medicine, ${ }^{2}$ Second Department of Internal Medicine, ${ }^{3}$ Department of General Medicine, Gunma University School of Medicine, Gunma, Japan.

Address for correspondence; Tsugiyasu Kanda, MD, Department of General Medicine, Gunma University School of Medi-

cine, 3-39-15, Showa-machi, Maebashi, Gunma 371-8511 Japan.

Received for publication September 20, 2000.

Revised and accepted Febuary 1, 2001. 


\section{Methods}

The study included 7 patients ( 2 men and 5 women, 16 to $70 \mathrm{yr}$.). The diagnosis of ARVD was made based on criteria published by McKenna, et al. ${ }^{16}$ These criteria are subdivided into major and minor criteria and are classified into six categories based on identification of the following: 1) global and/or regional dysfunction and structural alternations, 2) fatty or fibrofatty replacement of the right ventricular free wall, 3) repolarization abnormalities, 4) depolarization/conduction abnormalities, 5) arrhythmia and 6) family history. The diagnosis was based on the presence of the two major criteria; one major.plus two minor criteria; or four minor criteria. Patients presenting with complete right bundle branch block on the surface electrocardiogram were excluded because this conduction defect can mask late potentials, as demonstrated by Omen, et al. ${ }^{17)}$ As controls, we selected 241 patients who had no known heart disease and whose mean age waas $25.8+9.9$, (85 men and 156 women).

SAECG: A SAECG in the time domain was performed using a Marquette MAC 15 system 18-20) to record standard orthogonal leads $\mathrm{X}$, Y, and Z. The signals from the 3 leads were bandpass-filtered digitally with a high-pass bi-directional filter $(40 \mathrm{~Hz})$. The low-pass cutoff frequency was $250 \mathrm{~Hz}$. The signals were combined into a vector magnitude waveform, $\mathrm{V}(\mathrm{V}=\mathrm{x} 2+\mathrm{y} 2+\mathrm{z} 2)$. The following indexes were derived from this waveform of the filtered QRS: total filtered QRS duration (fQRS), the root-mean-squared voltage of the terminal $40 \mathrm{~ms}$ (RMS), and the duration of low amplitude signals (LAS) $<40 \mu \mathrm{V}$ in the terminal portion of the filtered QRS. As reported by Timmermans, et al using a $40 \mathrm{~Hz}$ high-pass filter, the normal values were: $\mathrm{fQRS}<122 \mathrm{~ms}$ for men; $\mathrm{fQRS}<115 \mathrm{~ms}$ for women; LAS $<41 \mathrm{~ms}$ and RMS $>20 \mu \mathrm{V}$ for both genders. Late potentials were considered positive if at least 2 of the above-mentioned variables were positive. We selected the vector magnitude method of Ozawa, et $a l^{14)}$ and showed the criteria in comparison with other reports (Table I).

Echocardiography: An echocardiogram were performed in all patients to evaluate right ventricular structural abnormalities and to measure right ventricular enddiastolic diameter and left ventricular ejection fraction. From M-Mode record-

Table I. Diagnostic Criteria of Late Potential by a Vector Magnitude Mmethod ${ }^{12)}$

\begin{tabular}{lllll}
\hline Authors & $\begin{array}{l}\text { High-pass filter } \\
(\mathrm{Hz})\end{array}$ & $\begin{array}{l}\text { Filtered QRS } \\
\text { duration }(\mathrm{msec})\end{array}$ & $\begin{array}{l}\text { Root means quare } \\
\text { voltage }(\mu \mathrm{V})\end{array}$ & $\begin{array}{l}\text { Low amplitude } \\
\text { signal }(\mathrm{msec})\end{array}$ \\
\hline $\begin{array}{l}\text { Simon, } \text { et al } \\
\text { Gomes, } \text { et al }\end{array}$ & 25 & $>110$ & and $>25$ & \\
Kucher, et al & 40 & $>114$ & or $<25$ & under $40 \mu \mathrm{V}>38$ \\
Nalos, et al & 40 & $>120$ & or 20 & under $20 \mu \mathrm{V}>30$ \\
Ozawa, et al & 40 & $>120$ & or $<20$ & under $40 \mu \mathrm{V}>40$ \\
\hline
\end{tabular}


ings, the thickness of the left ventricular wall and left ventricular dimensions were measured using American Society of Echocardiography standards. ${ }^{21}$ )

Arrhythmic patterns: Serial basal electrocardiograms and Holter monitoring were performed in all patients to assess electrical instability. Ventricular arrythmias, occuring before admission and before SAECG and endomyocardial biopsy, were considered representative of the patient's arrhythmic profile. There were 4 patients with sustained ventricular tachycardia or ventricular fibrillation and 2 patients with non-sustained ventricular tachycardia.

Angiography: Angiographic studies were performed in 5 cases, and included an evaluation of right ventricular morphology. ${ }^{21,22)}$ Left ventricular end-diastolic volume and ejection fraction were also determined. Coronary angiograms were performed to detect ischemic heart disease.

Endomyocardial biopsy: Endomyocardial biopsies of the right ventricle were obtained in 6 patients via a femoral vein approach using the long sheath technique. The samples were obtained at the junction between the ventricular septum and the anterior free wall, close to the apex. One to 3 biopsy specimens were obtained from each patient, fixed in $10 \%$ phosphate-buffered formalin, and then processed for histologic examination. The biopsied tissues were graded for the severity of fatty involvement and fibrosis using the following scale: mild, lesions involving less than $25 \%$ of the ventricular myocardium; moderate, lesions involving 25 to $50 \%$ of the myocardium; and severe, lesions involving 50 to $75 \%$ of the myocardium; and very severe, lesions involving 75 to $100 \%$ of the myocardium. Paraffin-embedded sections were serially cut and stained with hematoxylineosin. Abnormal values were established from a control group of transplanted patients: a percentage of myocytes $<63 \%$, a percentage of fatty tissue $>3 \%$, and a percentage of fibrous tissue $>15 \% .^{23,24)}$

\section{Results}

The main electrocardiographic, echocardiographic, Holter monitoring, SAECG, and histologic findings are presented in Table II.

12-lead ECGs and late potentials:These patients had 12-lead ECG abnormalities $(50 \%)$. Of the controls, 12 of 242 patients had ECG abnormalities, including an epsilon wave-like pattern (Figure 1) or nonspecific ST-T changes (5\%). Five patients had late potentials using a 40-Hz filter (Figure 2). Nineteen of the 241 control patients also had late positive late potentials $(8 \%)$.

Arrhythmic profile: The most severe spontaneous ventricular arrhythmias, recorded before admission, are summarized in Table II. Ventricular fibrillation was documented in 1 patient and sustained ventricular tachycardia in 3 cases. None of the control cases had severe spontaneous ventricular arrhythmias. 

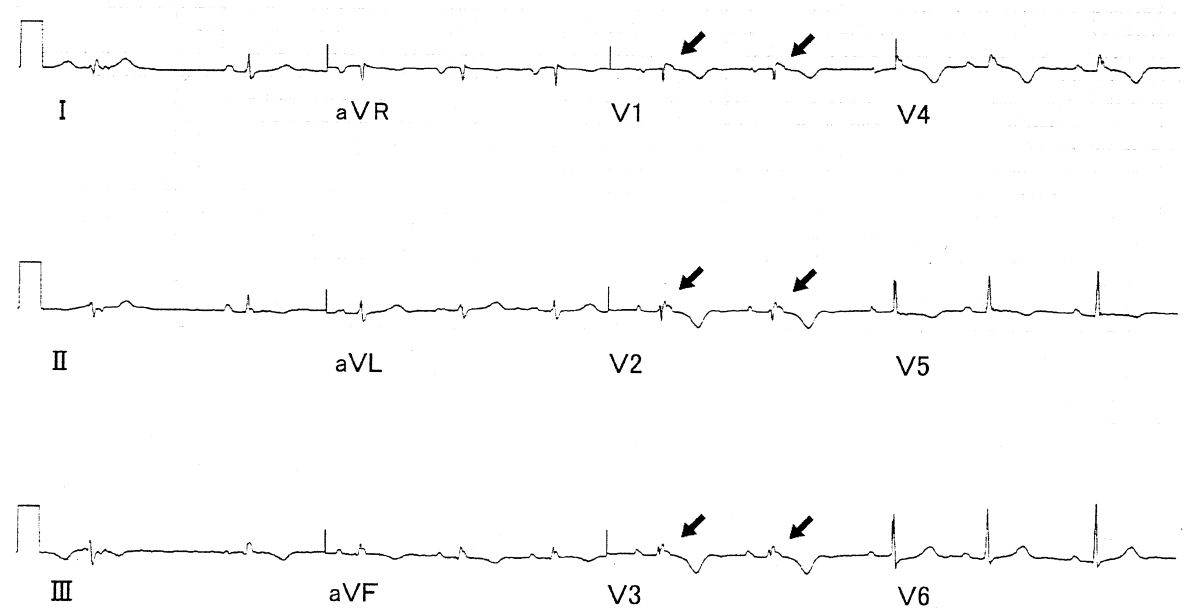

Figure 1. Electrocardiography in Patient No. 1 demonstrated epsilon waves (arroes) in V1 and V2.

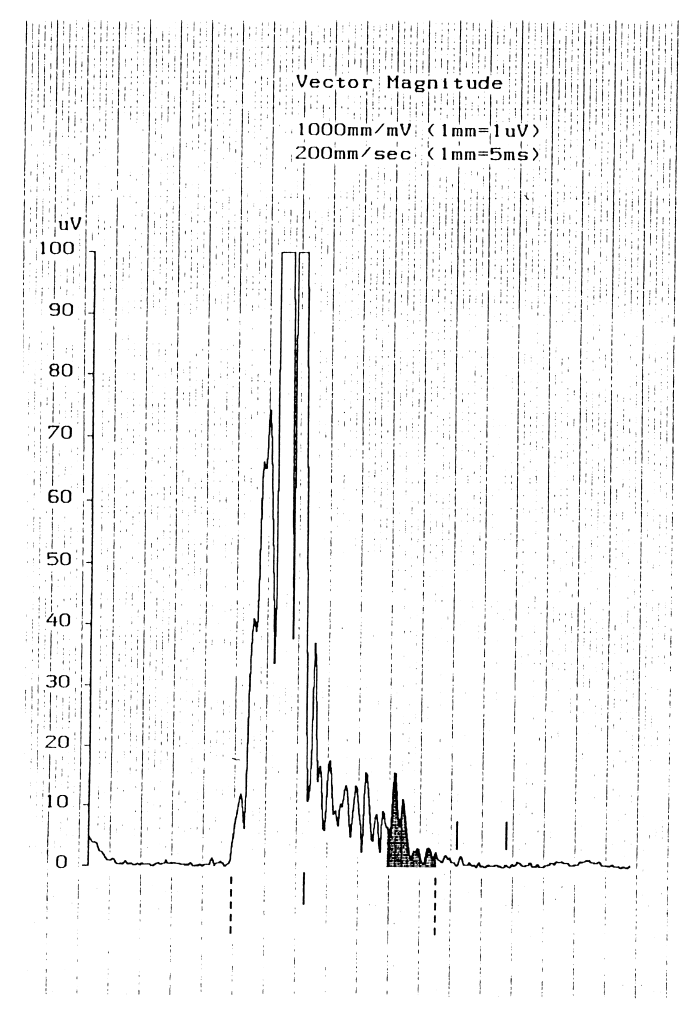

Figure 2. Patient No.3 had the positive late potentials as $40-\mathrm{HZ}$ filter $(\mathrm{fQRS}=165 \mathrm{~ms}, \mathrm{LAS}=106 \mathrm{~ms}, \mathrm{RMS}=4 \mu \mathrm{V})$. 
Histologic biopsy findings: Fatty tissue was observed in the biopsy specimen from 4 of the patients in whom right ventricle biopsies were performed (Figure 3). Interstitial fibrosis was also seen in 4 of these 6 patients, as shown in Table II.

\section{DISCUSSION}

Table II. Clinical Findings in Six Patients with ARVC

\begin{tabular}{|c|c|c|c|c|c|c|c|}
\hline Case No. & 1 & 2 & 3 & 4 & 5 & 6 & 7 \\
\hline $\begin{array}{l}\text { Electrocardio- } \\
\text { grahy }\end{array}$ & $\begin{array}{l}\text { Epsilon } \\
\text { Negative T }\end{array}$ & Normal & $\begin{array}{l}\text { Epsilon } \\
\text { Negative T }\end{array}$ & Negative $T$ & Normal & Normal & $\begin{array}{l}\text { QRS } \\
\text { widening }\end{array}$ \\
\hline $\begin{array}{l}\text { Late potential } \\
\text { Holter monotoring }\end{array}$ & $\begin{array}{l}\text { Positive } \\
\text { SVT }\end{array}$ & $\begin{array}{l}\text { Positive } \\
\text { SVT }\end{array}$ & $\begin{array}{l}\text { Positive } \\
\text { NSVT }\end{array}$ & $\begin{array}{l}\text { Positive } \\
\text { NSVT }\end{array}$ & $\begin{array}{l}\text { Negative } \\
\text { SVT }\end{array}$ & $\begin{array}{l}\text { Positive } \\
\text { SVT }\end{array}$ & $\begin{array}{l}\text { Positive } \\
\text { VF }\end{array}$ \\
\hline $\begin{array}{l}\text { Right ventricle } \\
\text { by echocardio- } \\
\text { graphy }\end{array}$ & Dilated & Dilated & Dilated & Dilated & Dilated & Normal & Dilated \\
\hline \multicolumn{8}{|l|}{$\begin{array}{l}\text { Biopsied } \\
\text { specimen }\end{array}$} \\
\hline $\begin{array}{l}\text { Fatty } \\
\text { replacement }\end{array}$ & Severe & Mild & Moderate & ND & ND & Mild & Moderate \\
\hline Fibrosis & Mild & Mild & Moderate & ND & ND & Moderate & Moderate \\
\hline
\end{tabular}

SVT $=$ sustained ventricular tachycardia; NSVT = non-sustained ventricular tachycardia; ND = not done.

\section{Left ventricle}
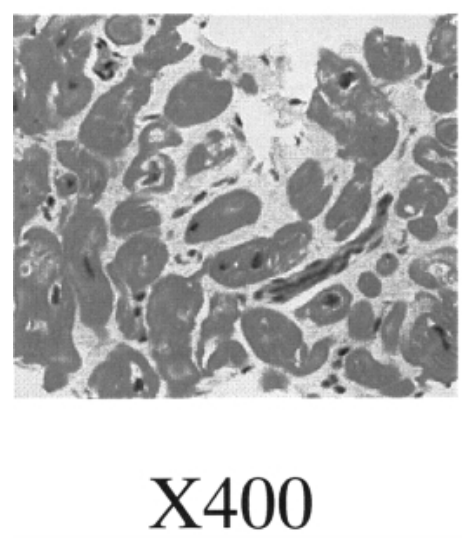

\section{Right ventricle}
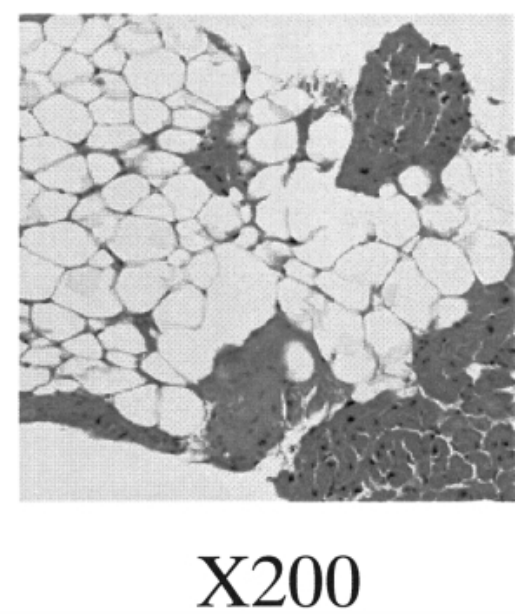

Figure 3. Patient No.1 had sustained ventricular tachycardia and a dilated right ventricular ventricle. Right ventricular biopsy samples showed significant fibrosis and extensive fatty infiltration. The left ventricle shows mild myocardial degeneration in the biopsied specimen. 
This study shows that SAECG can be useful as a screening test to detect patients with ARVD, in addition to Holter monitoring, echocardiography, and myocardial biopsies. Although the number of patients in the study was small, the sensitivity of SAECG was significant.

ARVD is recognized clinically as recurrent ventricular tachycardia of right ventricular origin and a cardiomyopathy limited to the right ventricle. ${ }^{1-6)}$ Localized hypokinesis in the right ventricle is usually demonstrated, and the right ventricle may be dilated. There is excessive adipose tissue in the subepicardium. Patients with ARVD have recurrent episodes of ventricular tachycardia with a left bundle branch block-like pattern that can usually be induced by electrical stimulation, suggesting a reentrant mechanism. Fragmented or delayed potentials are often recorded during endocardial mapping of the right ventricle. ${ }^{25)}$ These areas of slow conduction, in conjunction with endomyocardial biopsy findings of fatty infiltration, a decrease in myocardial fibers, and intramyocardial fibrosis in the dysplastic right ventricle, may cause inhomogeneity of activation and recovery and thus, promote reentry. ${ }^{25)}$

ARVD is usually diagnosed in patients between the ages of 20 and 50 years. A familial predisposition for ARVD has been described, suggesting that a genetic factor may be involved. ${ }^{1-6,8-16)}$ Only $10 \%$ of patients are diagnosed before the age of 20, probably because the arrhythmia is not apparent during this stage of life. However, patients with ARVD have an increased risk of cardiac sudden death. These events generally occur during sports activities or strenuous exercise in young adults and may be the first episode of a ventricular arrhythmia. ${ }^{1-4)}$ The finding that sudden death occurs even in young people suggests that the juvenile form of ARVD is not benign. Routine clinical examination is often normal, because the standard 12-lead ECG in sinus rhythm shows epsilon waves in only $30 \%$ of cases. ${ }^{25)}$ A screening test for detecting patients with ARVD is needed, since the SAECG procedure is neither complicated nor time consuming (about 10 minutes). ${ }^{15)}$ Moreover, it is cost-effective and only reguires 1 meter of recording paper. The reasons why we utilizede time domain method instead of frequency domain method to study the SAECG are as follows: ${ }^{26,27)}$ 1) Time domain method is well established and has good reproducibility, 2) Frequency domain method is well utilized. 3) A Marquette MAC 15 system, used in this study, includes the time domain method but not the frequency domain method. ${ }^{18-20)}$

Mehta, et $a{ }^{28}$ ) reported that in patients with ARVD the extent of abnormality of the SAECG variables is proportional to the degree of right ventricular cavity enlargement and indicative of the severity of right ventricular dysfunction. Turrini, et $a^{29)}$ reported that SAECG variables and right ventricular ejection fraction correlate with the extent of myocardial fibrosis on biopsy in ARVD. They 
also showed that an increased percentage of fibrous tissue was a significant univariate predictor of late potentials and that reduced right ventricular ejection fraction plays an essential role in the spontaneous manifestation of sustained ventricular arrhythmia. However, relatively mild cases of ARVD may often show no SAECG abnormalities.

In our study the prevalence of late potentials was $86 \%$. Generally, 50 to 80 $\%$ of patients with right ventricular dysplasia have abnormal SAECGs, with a specificity in the range of 90 to $100 \% .^{30)}$ Kinoshita, et $a l^{31)}$ suggested that an fQRS duration $>110 \mathrm{~ms}$ or an area ratio 2 (40 to $100 / 0$ to $40 \mathrm{~Hz}$ ) $>75$, could serve as criteria for screening for detecting patients with ARVD, and reported that these criteria provided a diagnostic sensitivity of $100 \%$, specificity of $94 \%$, and total predictive accuracy of $100 \%$. In this study, we used only the time-domain SAECG, with more common but more restricted criteria, and found only one patient who did not show late potentials. We believe that SAECG is useful for the identification of patients with ARVD.

\section{REFERENCES}

1. Marcus FI, Fontaine GH, Guiraudon G, et al. Right ventricular dysplasia. A report of 24 adult cases. Circulation 1982; 65: 384-98.

2. Thiene G, Nava A, Corrado D, Rossi L, Penneli N. Right ventricular cardiomyopathy and sudden death in young people. N Engl J Med 1988; 318: 129-33.

3. Corrado D, Thiene G, Nava A, Rossi L, Pennelli N. Sudden cardiac death in young competitive athletes: clinicopathologic correlations in 22 cases. Am J Med 1990; 89: 588-96.

4. Daliento L, Turrini P, Nava A, et al. Arrhythmogenic right ventricular cardiomyopathy in young versus adult patients: similarities and differences. J Am Coll Cardiol 1995; 25: 655-64.

5. Basso C, Thiene G, Corrado D, Angelini A, Nava A, Valente M. Arrhythmogenic right ventricular cardiomyopathy: dysplagia, dystrophy or myocarditis? Circulation 1996; 94: 983-91.

6. Richardson P, McKenna W, Bristow M, et al. Report of the 1995 World Health Organization / International Society and Federation of Cardiology Task Force on the Definition and Classification of Cardiomyopathies. Circulation 1996; 93: 841-2.

7. Corrado D, Basso C, Thiene G, et al. Spectrum of clinicopathologic manifestations of arrhythmogenic right ventricular cardiomyopathy / dysplasia: a multicenter study. J Am Coll Cardiol 1997; 30: 1512-20.

8. Pinamonti B, Sinagra G, Salvi A, et al. Left ventricular involvement in right ventricular cardiomyopathy. Am Heart J 1992; 123: 711-24.

9. Nava A, Thiene G, Canciani B, et al. Familial occurrence of arrhythmogenic right ventricular dysplasia: a study involving nine families. J Am Coll Cardiol 1988; 12: 1222-8.

10. Rampazzo A, Nava A, Erne P, et al. A new locus for arrhythmogenic right ventricular cardiomyopathy (ARVD2) maps to chromosome 1q42-q43. Hum Mol Genet 1995; 4: 2152-4.

11. Severini GM, Krajinovic M, Pinamonti B, et al. A new locus for arrhythmogenic right ventricular dysplagia on the long arm of chromosome 14. Genomics 1996; 31: 193-200.

12. Ozawa Y. Late potential. Cardiac pacing 1989; 5: 285-317 (in Japanese).

13. Yakubo S, Ozawa Y, Saito Y, et al. Normal limits of high-resolution signal-averaged ECG parameters of Japanese adult men and wemen. J Electrocardiol 2000; 33: 225-31.

14. Rampazzo A, Nava A, Miorin M, et al. ARVD 4, a new locus for arrhythmogenic right ventricular cardiomyopathy, maps to chromosome 2 long arm. Genomics 1997; 45: 259-63. 
15. Coonar AS, Protonotarios N, Tsatsopoulou A, et al. Gene for arrhythmogenic right ventricular cardiomyopathy with diffuse nonepidermolyic palmoplantar keratoderma and wolly hair (Naxos disease) maps to 17q21. Circulation 1998; 97: 2049-58.

16. MaKenna WJ, Thiene G, Nava A, et al. Diagnosis of arrhythmogenic right ventricular dysplasia / cardiomyopathy. Br Heart J 1994; 71: 215-8.

17. Ommen SR, Hammill SC, Bailey KR. Failure of signal-averaged electrocardiography with use of time-domain variables to predict inducible ventricular tachycardia in patients with conduction defects. Mayo Clin Proc 1995; 70: 132-6.

18. Timmermans C, Ector H, Haisty KW, et al. Signal-averaged ECG parameters in cardiac normals using Frank lead system and Fourier transform filter and gender specific diffences: a multicenter study. PACE 1994; 17: 303-11.

19. Yakubo S, Ozawa Y, Tanigawa N, Yasugi T. Detection of late potentials. Comparison of two commercial highresolutional ECG systems. J Electrocardiol 1992; 25: 151-5.

20. Hammill SC, Tchou PJ, Kienzle MG, Haisty KW, Ozawa Y, Underwood DA. Establishment of signal-averaged electrocardiographic criteria with Frank XYZ leads and spectal filter used alone and in combination with ejection fraction to predict inducible ventricular tachycardia in coronary artery disease. Am J Cardiol 1992; 70: 316-20.

21. Sahn OJ, DeMaria AN, Kisslo J, Weyman A. Recommendations regarding quantitation in M-mode echocardiography: results of a survey of echocardiographic measurement. Circulation 1978; 58: 1072-83.

22. Daubert C, Descaves C, Foulgoc J, Bourdonnec C, Laurent M, Gouffault J. Critical analysis of cineangiographic criteria for diagnosis of arrhythmogenic right ventricular dysplasia. Am Heart J 1988; 115: 448-59.

23. Angelini A, Thiene G, Boffa GM, et al. Endomyocardial biopsy in right ventricular cardiomyopathy. Int J Cardiol 1993; 40: 273-82.

24. Angelini A, Basso C, Nava A, Thiene G. Endomyocardial biopsy in arrhythmogenic right ventricular cardiomyopathy. Am Heart J 1996; 132: 203-6.

25. Fontaine G, Frank R, Tonet JL, et al. Arrhythmogenic right ventricular dysplasia: a clinical model for the study of chronic ventricular tachycardia. Jpn Circ J 1983; 48: 515-38.

26. Simson MB, Untereker WJ, Spielman SR, et al. Relation between late potentials on the body surface and directly recorded fragmented electrograms in patients with ventricular tachycardia. Am J Cardial 1983; 51: $105-12$.

27. Harber R, Jilge G, Pulter R, et al. Comparison of frequency and time domain analysis of the signal-averaged electrocardiogram in patients with ventricular tachycardia and coronary artery disease; methodologic validation and clinical relevance. J Am Coll Cardiol 1988; 12: 150-8.

29. Mehta D, Goldman M, David O, Gomes A. Value of quantitative mesurement of signal-averaged electrocardiographic variables in arrhythmogenic right ventricular dysplasia: correlation with right ventricular cavity dimensions. J Am Coll Cardiol 1996; 28: 713-9.

30. Turrini P, Angelini A, Thiene G, et al. Late potentials and ventricular arrhythmias in arrhythmogenic right ventricular cardiomyopathy. Am J Cardiol 1999; 83: 1214-9.

31. Leclercq JF, Coumel P. Late potentials in arrhythmogenic right ventricular dysplasia. Prevalence, diagnostic and prognostic values. Eur Heart J 1993; 14 (suppl E): 80-3.

32. Kinoshita O, Fontaine G, Rasas F, et al. Time and frequency-domain analyses of the signal-averaged ECG in patients with arrhythmogenic right ventricular dysplasia. Circulation 1995; 91: 715-21. 